\title{
Diagnosis and Management of Internal Hemorrhoids: A Brief Review
}

\author{
P. Agus Eka Wahyudi, Stephen William Soeseno, and Febyan Febyan
}

\section{ABSTRACT}

\begin{abstract}
Hemorrhoidal disease is a pathological condition due to the abnormal engorgement of the arteriovenous plexus beneath the anal mucosa. Anatomically, it can be located under the skin on the outer part of the dentate line, known as external hemorrhoid; or inside the anus on the proximal part of the dentate line, called internal hemorrhoid. Internal hemorrhoid may further develop from a painless anal mass into protruded and painful mass throughout the anal canal, often accompanied by inflammation and more severe symptoms. Various management strategies need to be considered carefully to ensure the success of therapy and improve the quality of life of patients with internal hemorrhoids. Conservative management is the initial stage that can be performed, including the provision of high-fiber nutrition, education related to bathroom habits, and the use of flavonoid regimens. Surgical therapy can be divided into outpatient intervention and conventional surgeries. This review will encompass the comprehensive diagnostic approach and management of internal hemorrhoids to help clinicians understand the appropriate management and provide better clinical benefits for the patients.
\end{abstract}

Keywords: Hemorrhoids, anorectal, anal bleeding, surgical management.
Submitted: August 15, 2021

Published: September 06, 2021

ISSN: 2593-8339

DOI: $10.24018 /$ ejmed.2021.3.5.1014

\section{P. A. E. Wahyudi}

General Surgery Department, Sanglah General Hospital Denpasar, Bali, Indonesia.

S. W. Soeseno*

Bunda Mulia Hospital Cikarang, West

Java, Indonesia.

(e-mail: stephensoeseno@gmail.com)

Febyan Febyan

Bhayangkara Denpasar Hospital,

Denpasar, Bali, Indonesia.

*Corresponding Author

\section{INTRODUCTION}

Hemorrhoidal disease (HD) is a common pathological anorectal condition in adulthood. It is caused by the increased pressure and abnormal dilatation of the hemorrhoidal vascular plexus. In the United States, HD becomes the third most common outpatient gastrointestinal findings affecting about $75 \%$ of American adults with the estimation of four million visits every year [1]. The prevalence is highest in the Caucasian race between the ages of 45 to 65 [1]. Hemorrhoids may develop into two types, i.e., internal and external hemorrhoids. In addition, internal hemorrhoids may develop into prolapsing hemorrhoids through the anus outside the body, which eventually becomes irritated and painful [2].

Hemorrhoids symptoms are often initiated by painless, bright red blood covering the stool and the sensation of impacted stool. Patients may also experience perineal itching due to the presence of mucus discharge and fecal soiling [3]. Although it is a non-threatening condition, it impacts lifestyle and social burden. Therefore, it is important to understand comprehensive management to ensure the long-term quality of life of HD patients. [4]. This review aims to evaluate the diagnosis and management of internal hemorrhoids by the current literature reviews published.

\section{PAThophysiology}

Theoretically, hemorrhoids are actually a highly vascular cushion containing the arterioles, veins, smooth muscle, the elastic and connective tissue found within the submucosal space and are considered part of the normal anatomy of the anal canal [5]. The anal canal comprises three main cushions in the left lateral, right anterior, and right posterior positions [6]. This collection of various tissues supports the structure of the anal canal and contributes to $15 \%-20 \%$ of resting pressure within the canal. Each cushion surrounds the arteriovenous communications between the superior and middle rectal arteries terminal branches and the superior, middle, and inferior rectal veins [7]. In addition, hemorrhoidal cushions present with several crucial roles within the anal canal. It mainly retains anal continence and prevents stool leakage when there is increased intraabdominal pressure (e.g., straining, coughing, and sneezing) by engorging with blood and causing the closure of the anal canal [8]. In addition, hemorrhoidal cushions act to protect the underlying anal sphincters during defecation. It also has a sensory function to differentiate between liquid, solid, and gas and the subsequent decision to evacuate [7]. There are several factors contribute to the development of pathologic changes within the hemorrhoidal cushions, such as constipation, prolonged straining, exercise, nutrition (low fiber intake), pregnancy, irregular bowel habits (diarrhea or constipation), genetics problem, and the absence of valve within the hemorrhoidal veins [9]. All these factors lead to rising pressure within the submucosal arteriovenous plexus, ultimately causing subsequent swelling of the cushions, increased laxity of the supporting connective tissue, and protrusion of hemorrhoids throughout the anal canal [10]. 


\section{Diagnosis \& DifFERENTIAL Diagnosis}

Some anorectal conditions demonstrate similar symptoms to those associated with hemorrhoids (Table I). Some conditions must be considered carefully because the symptoms may be related to serious conditions, such as inflammatory bowel disease or cancer. [3]. To differentiate, colonoscopy can be performed in patients with changes in bowel habits, weight loss, abdominal pain, and rectal bleeding with blood in the stool, or any family history with colon cancer [3]. Physical examination for hemorrhoids should be performed, such as abdominal examination, an inspection of the perineum, and digital rectal examination. In some cases, digital rectal examination alone may not exclude internal hemorrhoids from external hemorrhoids; hence anoscopy is required. The visualization view on anoscopy in internal hemorrhoids shows dilated purplish-blue veins, and when prolapsed, the veins appear glistening dark pink resembling tender masses at the anal margin. Meanwhile, external hemorrhoids may appear less pink and, if thrombosed, are acutely tender with a more purplish shade [2]. The American Society of Colon and Rectal Surgeons recommends assessing the patient with anoscopy and further endoscopic evaluation if there is a concern for inflammatory bowel disease or cancer [11].

TABLE I: DIFFERENTIAL DIAGNOSIS OF HEMORRHOIDS [12]

\begin{tabular}{|c|c|c|}
\hline Diagnosis & Historical Features & $\begin{array}{c}\text { Physical } \\
\text { Examination } \\
\text { Findings } \\
\end{array}$ \\
\hline Skin Tags & $\begin{array}{l}\text { Previous history of } \\
\text { healed hemorrhoids, } \\
\text { with no bleeding. }\end{array}$ & $\begin{array}{l}\text { Tags resemble skin- } \\
\text { colored mass and are } \\
\text { around the anus, not } \\
\text { on the mucosa. }\end{array}$ \\
\hline Anal Fissure & $\begin{array}{l}\text { Bleeding with bowel } \\
\text { movement and tearing } \\
\text { pain. }\end{array}$ & $\begin{array}{lr}\text { Painful } & \text { rectal } \\
\text { examination } & \text { with } \\
\text { fissure } & \end{array}$ \\
\hline Perianal Abscess & Gradual onset of pain & $\begin{array}{l}\text { Tender mass covered } \\
\text { with skin as opposed } \\
\text { to the rectal mucosa. }\end{array}$ \\
\hline Anal Cancer & $\begin{array}{l}\text { Pain around the anus, } \\
\text { weight loss in } \\
\text { advanced cases }\end{array}$ & $\begin{array}{l}\text { Ulcerating lesion of } \\
\text { the anus }\end{array}$ \\
\hline Anal Condylomata & $\begin{array}{l}\text { Anal mass without } \\
\text { bleeding; history of } \\
\text { anal intercourse }\end{array}$ & $\begin{array}{l}\text { Cauliflower-like } \\
\text { lesions }\end{array}$ \\
\hline Colorectal Cancer & $\begin{array}{l}\text { Weight loss, blood in } \\
\text { stool, abdominal pain, } \\
\text { change in bowel } \\
\text { habit, family history } \\
\text { with cancer }\end{array}$ & $\begin{array}{l}\text { Abdominal mass or } \\
\text { tenderness. }\end{array}$ \\
\hline $\begin{array}{l}\text { Inflammatory Bowel } \\
\text { Disease }\end{array}$ & $\begin{array}{l}\text { Abdominal pain, } \\
\text { constitutional } \\
\text { symptoms, diarrhea, } \\
\text { family history }\end{array}$ & $\begin{array}{l}\text { Normal external } \\
\text { rectal examination; } \\
\text { rarely, fistula, colitis } \\
\text { on anoscopy. }\end{array}$ \\
\hline
\end{tabular}

\section{Classification}

In general, hemorrhoids can be classified into two types, i.e., external and internal, which are classified anatomically based on their location relative to the dentate line. The external hemorrhoids are located distally to the dentate line and are lined by the modified squamous epithelium called anoderm cells. These structures contain a tremendous amount of innervation from the pain nerve tissue, making the external hemorrhoids become extremely painful on thrombosis. The thrombosis of external hemorrhoids occurs when there is a blood clot formation within the wall of the anal skin around the hemorrhoids. The blood clot formation causes swelling in the outer anal canal, causing persistent bleeding and severe pain that generally settled for 48 hours [13].

On the other hand, internal hemorrhoids are located proximally to the dentate line and are lined by the columnar epithelium. The overlying columnar epithelium is viscerally innervated; thus, newly developing internal hemorrhoids generally do not cause pain or are sensitive to touch [14]. However, at the stage where the internal hemorrhoids have completely prolapsed, one may experience severe pain. The grading of internal hemorrhoids can be divided into I to IV, which will further determine the management plan for the patient (Fig. 1). Grade I is characterized by painless anal bleeding or asymptomatic outgrowth of anal mucosa due to the engorgement of underlying arteriovenous plexus and connective tissue. Grade II is characterized by painless anal bleeding with prolapsing hemorrhoid on straining but may spontaneously reduce. Grade III is characterized by painless anal bleeding with prolapsing hemorrhoids thorough the anal canal, which can only be manually reduced. At this stage, the patients are often accompanied by pruritus and fecal soiling due to the blockage. Lastly, grade IV is characterized by painless or painful anal bleeding with irreducible prolapsing hemorrhoids, often accompanied by chronic local inflammatory changes [15].
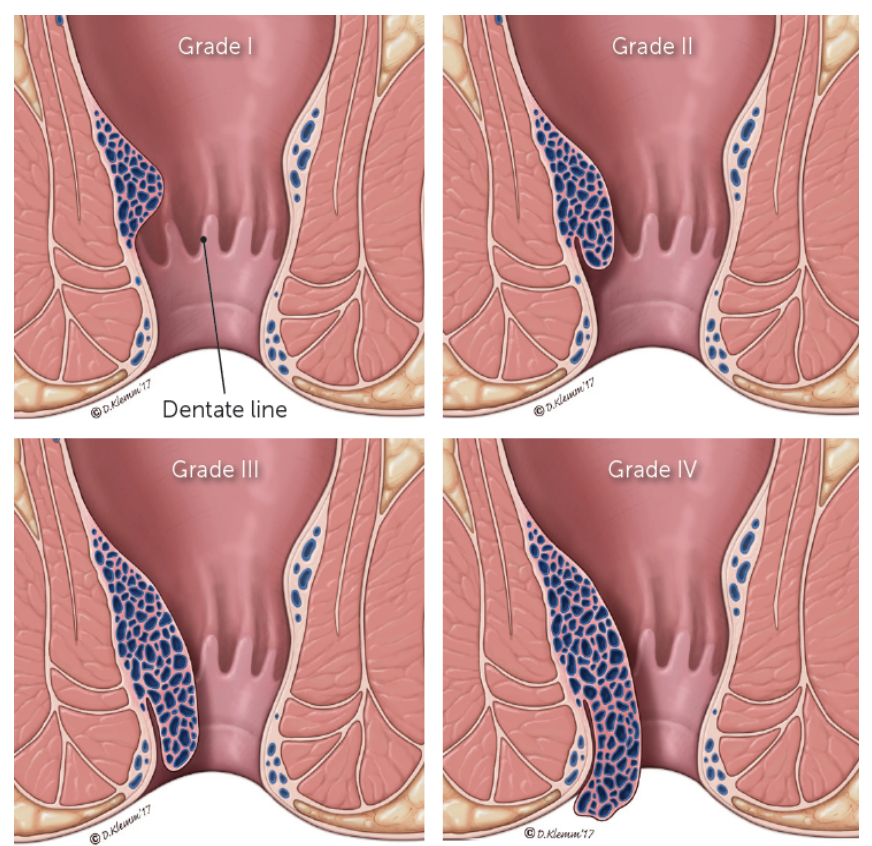

Fig. 1. Classification of internal hemorrhoids [16].

\section{MAnAGEMENT}

\section{A. Conservative Management}

Constipation and diarrhea have been acknowledged as the main contributing factors in the development of hemorrhoidal diseases. Therefore, recommendations suggest that adequate fiber and fluid intake may improve symptoms. Integrated patient education should be addressed regarding the consumption of daily dietary fiber 25-30 grams per day, drinking 6 to 8 cups of non-caffeinated drinks, and osmotic laxatives as necessary. Dietary fiber should be started from a small amount and increase gradually so that the patients do 
not develop an adverse reaction, such as abdominal cramping and bloating [17].

Moreover, the patients should be advised to avoid unhealthy bathroom habits, including excessive straining on the toilet and reading while in the bathroom. A prolonged sitting position in an attempt to defecate for more than 10-15 minutes causes an increase in abdominal pressure and further contributes to hemorrhoids engorgement. Topical preparations including suppositories, steroid creams, and medicated wipes are available for this condition, but no adequate evidence supports long-term success in treating hemorrhoids with these topical products [18].

Oral flavonoids-derivatized phlebotropic drug, such as micronized purified flavonoid fraction (MPFF), consists of $90 \%$ micronized diosmin and $10 \%$ hesperidin, and is commonly used in clinical treatment. This preparation helps in increasing venous wall tone and lymphatic drainage, further reducing the capillary hyperpermeability by defending the microcirculation from inflammatory processes. A meta-analysis of flavonoids for hemorrhoidal management, involving 14 randomized trials and 1514 patients, suggested that flavonoids decreased the risk of bleeding by $67 \%$, persistent pain by $65 \%$, and itching by $35 \%$, with a recurrence rate of $47 \%$ [19].

\section{B. Outpatient Interventions}

If the conservative management does not provide maximum results, non-surgical outpatient management can be considered to treat internal hemorrhoids. These interventions are simple procedures that can be performed in the surgeon's office without anesthesia or require only local anesthesia. Some examples of this type of treatment are rubber band ligation, sclerotherapy, and infrared coagulation.

- Rubber Band Ligation (RBL)

This method is the most frequent anorectal outpatient procedure performed in the surgery department. It is indicated for grade II and III internal hemorrhoids [20]. Rubber band ligation does not necessarily require any local anesthetic (Fig. 2 ). The patient lies in prone-jacknife or left lateral position, and the procedure is performed through an anoscope. The ligation procedure is assisted using the McGivney forceps ligator and the suction ligator. Small band rings are applied tightly at the base of the internal hemorrhoid, specifically at half a centimeter above the dentate line, to prevent the ring placement into somatically innervated nerve tissue. This procedure aims to make hemorrhoid tissue necrotic, leaving only a scar fixated on the rectal mucosa. Ligated hemorrhoidal tissue will undergo ischemia and become necrotic in 3-5 days, and then an ulcerated tissue bed will form. Complete healing generally occurs within a few weeks of the procedure [20].

The success rate of RBL ranges from 69\%-97\%. Postsurgical recurrences may occur in $6.6 \%-18 \%$ of patients; however, a subsequent treatment course can be done to minimize its occurrence [20]. Longman et al. [22] described different rates of complications following RBL, ranging from 3\%-18.8\%. Izadpanah et al. [23] summarized that $14 \%$ of 8,060 patients from 39 studies experienced post-banding complications, including severe pain $(5.8 \%)$, rectal hemorrhage (1.7\%), and anal fistula $(0.4 \%)$.

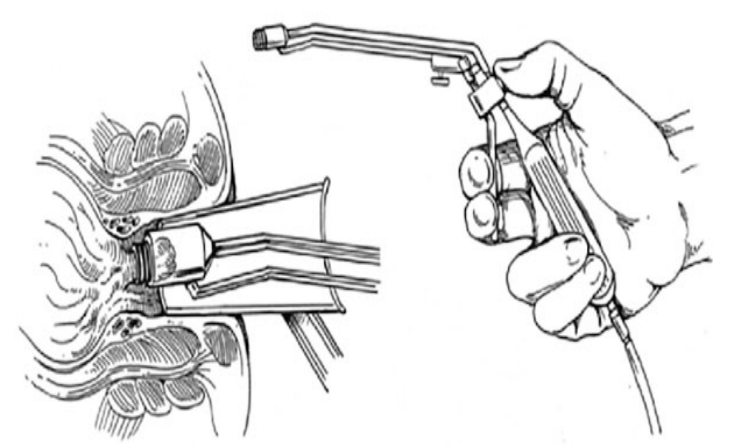

Fig. 2. Rubber band ligation of internal hemorrhoid using the suction ligator [21].

- Sclerotherapy

This method is one of the oldest forms of non-operative hemorrhoid management, first published in 1869 by Morgan in Dublin. It is mainly indicated for improtruded (grade I and II) internal hemorrhoids or in patients consuming regular anticoagulants. This procedure is administered by injecting 5 $\mathrm{mL}$ of $5 \%$ phenol in oil, $5 \%$ quinine and urea, or hypertonic (23.4\%) salt solution at the base of internal hemorrhoid to induce thrombosis of the blood vessels, sclerosis of connective tissue, and shrinkage and fixation of overlying mucosa [23]. An anoscope may be used to assist the procedure. Sclerotherapy is a simple procedure requiring no anesthesia and takes only minutes to perform [24].

A trial study of sclerotherapy showed improvement and successfully cured $82 \%$ of patients, followed by $98 \%$ of patients after second sclerotherapy [25]. There are still limited data on the efficacy of sclerotherapy. Nevertheless, a recent trial demonstrated a $20 \%$ success rate at one year in treating grade III hemorrhoids [26]. The results were found significantly better for the treatment of grade I hemorrhoids. A recent study by Moser et al. [27] compared the efficacy of polidocanol, a non-ester local anesthetic approved for use by the United States Food and Drug Administration, with 88\% of patients treated successfully in 12-weeks follow up. Although there are no randomized data to support the use of sclerotherapy in anticoagulated patients, a case series described by Yano et al. [26] reported no difference in postsurgical bleeding rates from 37 patients receiving antiplatelet therapy or anticoagulant therapy. Although sclerotherapy is a minimally invasive procedure, it may also cause complications, including pain which is variably reported in $70 \%$ of patients [24].

- Infrared Coagulation (IRC)

The principle of IRC therapy aims to apply infrared light waves directly to the hemorrhoidal tissue to induce coagulation and evaporates the water content inside the cell, causing shrinkage of the hemorrhoid tissue [28]. As with sclerotherapy, IRC is indicated for improtruded (grade I and II) internal hemorrhoids. Firstly, a probe is applied to the base of hemorrhoid using the anoscope (Fig. 3) with a contact time between 1.0 to 1.5 seconds, depending on the intensity and wavelength of the coagulator. The necrotic tissue is seen as a white spot and eventually heals with fibrosis. The IRC is not suitable for large or prolapsing hemorrhoids conditions [28], [29]. The efficacy of IRC is similar to RBL, and pain complications are minimal due to the lower volume of tissue necrosis [30]. Although a potential alternative to RBL, this 
procedure is still limited because it is quite expensive and requires a longer learning curve.

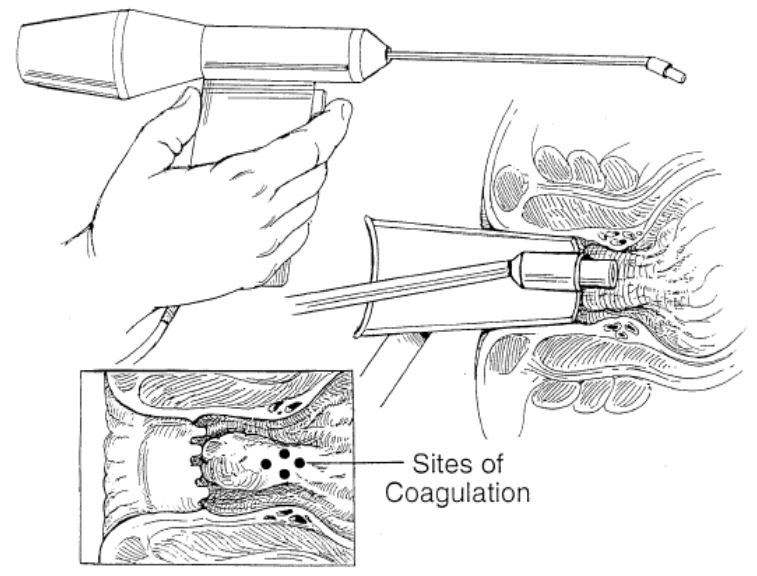

Fig. 3. Infrared coagulation procedure [31].

\section{Surgical Management}

\section{- Hemorrhoidectomy}

Hemorrhoidectomy is the most effective procedure in hemorrhoid management by completely excising the redundant tissue causing the bleeding and protrusion. It provides the lowest recurrence rate compared to other procedures. This procedure can be assisted using scissors, diathermy, or vascular sealing devices under perianal anesthesia [32]. Surgical procedure is mainly indicated if non-surgical management fails. In clinical practice, excisional hemorrhoidectomy is also indicated for grade III and IV internal hemorrhoids [32]. Although simple and effective, the drawback of this procedure is significant postoperative pain. Another major post-operative complication is acute urinary retention, affecting $2 \%-36 \%$ of the patients. This procedure is often followed by the removal and pathological examination of hemorrhoidal tissue, particularly if malignancy is suspected. However, hemorrhoidal specimens may not be pathologically examined if there is no suspicion of malignancy [33].

- Stapled Hemorrhoidopexy

This procedure is an alternative surgical procedure that is mainly indicated for grade II and III internal hemorrhoids. It is performed by excising the redundant tissue and subsequently fixate hemorrhoidal tissue back into the rectal wall [34]. The difficulty that may occur during this procedure is the application of non-absorbable purse-string sutures in a circumferential fashion approximately four centimeters proximally from the dentate line to avoid sphincter muscle involvement. If the purse-string suture is overly distal to the rectum, it will cause more post-operative pain, but the stapler may create a full-thickness excision through the rectal wall if it is too proximal. This condition could lead to abscess or fistula formation, requiring another surgical revision [34]. Therefore, it is crucial for the surgeon to be familiar with the certain stapling device prior to being executed. Other potentially occurring complications are sphincter muscle injury, bleeding, stenosis, anastomotic line dehiscence, and recto-vaginal fistula formation. Gravie et al. [35] in a randomized controlled trial (RCT), compared open hemorrhoidectomy to stapled hemorrhoidopexy and discovered several advantages of this procedure, including lesser post-operative pain during bowel movement, earlier post-operative bowel movement, shorter hospital stays, and lesser pain killer requirements. Giordano et al. [36] also supported that stapled hemorrhoidopexy is a safer technique for managing hemorrhoids; however, it carries a significantly higher incidence of long-term recurrences than conventional hemorrhoidectomy. Malyadri et al. [37] reported that stapled hemorrhoidopexy was significantly quicker to perform compared with open hemorrhoidectomy. Hence, hospitalization and duration of daily activity resumption were less in the stapled hemorrhoidopexy group than open hemorrhoidectomy. Contrary, a multicenter RCT study by Nystrom et al. [38] reported equal rates of recurrence and better symptomatic relief with open hemorrhoidectomy. Therefore, the application of this procedure has been reduced among surgeons in Europe.

\section{COMPLiCATiOnS}

Various complications may occur in internal hemorrhoid cases. They include bleeding, infection, fecal incontinence, urinary retention, and anal stenosis. Fortunately, bleeding can frequently be controlled with anal packing or suturing [17]. Infection is a rare event, but may develop into serious septicemia if not acknowledged promptly and treated with intravenous antibiotics [39]. Urinary retention can be managed by inserting temporary catheterization and normally resolved within three days after surgery [40]. Bulk-forming agents, such as oral fiber supplements can be given to patient with post-surgical fecal incontinence [17]. Lastly, anal stenosis may be managed with anal dilatations [40].

\section{PROGNOSIS}

The overall prognosis of internal hemorrhoids is satisfactory. Most early developing internal hemorrhoids can be resolved with conservative medical treatment, with recurrence rates ranging from $10 \%-50 \%$ over five years. Surgical management is an alternative for ineffective conservative and conventional approaches, with a recurrence rate of less than $5 \%$ [41].

\section{CONCLUSION}

Internal hemorrhoid is a common pathological anorectal finding but a complex disease. The symptoms and signs of internal hemorrhoids should be evaluated thoroughly, along with the determination of clinical grading. Various options for managing internal hemorrhoids and specific therapeutic approaches should depend on each individual reasoning and clinical factors. Lifestyle modifications, including high-fiber diet intake, healthy bathroom habits, and the administration of phlebotropic agents, should be initially performed. Outpatient interventions and surgical approaches should be applied when other modalities fail. Management of therapy is extremely important to prevent further complications from the internal hemorrhoids. 


\section{REFERENCES}

[1] R. F. Fontem, D. Eyvazzadeh (August 2020). Internal hemorrhoid. Treasure Island (FL): StatPearls Publishing [Online]. Available from: https://www.ncbi.nlm.nih.gov/books/NBK537182/.

[2] R. C. G. Russel, N. S. Williams, C. J. K. Bulstrode, Ed., Bailey \& Love's Short Practice of Surgery, 23rd ed. London, U.K.: Oxford Press, 2003, pp. 1128.

[3] A. G. Acheson, J. H. Scholefield, "Management of haemorrhoids," $B M J$, vol. 336, no. 7640, pp. 380-383, Feb. 2008.

[4] E. B. Sneider, J. A. Maykel, "Diagnosis and management of symptomatic hemorrhoids," Surg. Clin. North. Am., vol. 90, no. 1, pp. 17-32, Feb 2010.

[5] S. R. Brown, "Haemorrhoids: an update on management," Ther. Adv. Chronic Dis., vol. 8, no. 10, pp. 141-147, Oct 2017.

[6] N. Margetis, "Pathophysiology of internal hemorrhoids," Ann. Gastroenterol., vol. 32, no. 3, pp. 264-272, May 2019.

[7] J. Fleshman, R. Madoff, "Hemorrhoids," in Current Surgical Therapy, 8th ed., J. Cameron. Philadelphia: Elsevier, 2004, pp. 245-252.

[8] F. Aigner, H. Gruber, F. Conrad, et al., "Revised morphology and hemodynamics of the anorectal vascular plexus: impact on the course of hemorrhoidal disease," Int. J. Colorectal. Dis., vol. 24, no. 1, pp. 105-113, Jan 2009.

[9] Harvard Women's Health Watch (August 2020). Hemorrhoids and what to do about them. Harvard Health Publishing [Online]. Available from: https://www.health.harvard.edu/diseases-and-conditions/ hemorrhoids_and_what_to_do_about_them.

[10] V. M. Stolfi, P. Sileri, C. Micossi, et al., "Treatment of hemorrhoids in day surgery: stapled hemorrhoidopexy vs Milligan-Morgan hemorrhoidectomy," J. Gastrointest. Surg., vol. 12, no. 5, pp. 795-801, May 2008.

[11] P. Cataldo, C. N. Ellis, S. Gregorcyk, et al., Standards Practice Task Force, The American Society of Colon and Rectal Surgeons, USA, "Practice parameters for the management of hemorrhoids (revised)," Dis. Colon Rectum., vol. 48, no. 2, pp. 189-194, Feb 2005.

[12] L. Abramowitz, G. H. Weyandt, B. Havlickova, et al., "The diagnosis and management of haemorrhoidal disease from a global perspective," Aliment. Pharmacol. Ther. vol. 31, no. 1, pp. 1-58, May 2010.

[13] M. L. Welton, G. J. Chang, A. A. Shelton, "Hemorrhoids," in Current Surgical Diagnosis and Treatment, 12th ed., G. M. Doherty, Ed. New York: Lange, 2006, pp. 738-764.

[14] J. Cintron, H. Abcarian, "Benign anorectal: hemorrhoids," in The ASCRS Textbook of Colon and Rectal Surgery, B. G. Wolff, J. W. Fleshman, D. E. Beck, et al., Ed., New York: Springer-Verlag, Inc, 2007, pp. 156-177.

[15] D. Yeo, K. Y. Tan, "Hemorrhoidectomy —-making sense of the surgical options," World J. Gastroenterol., vol. 20, no. 45, pp. 16976-16983, 2014.

[16] T. Mott, K. Latimer, C. Edwards C, "Hemorrhoids: diagnosis and treatment options," AAFP, vol. 97, no. 3, pp. 172-179, 2018.

[17] D. E. Beck, P. L. Roberts, J. L. Rombeau, et al., The ASCRS Manual of Colon and Rectal Surgery, New York, NY: Springer, 2009, pp. 225257.

[18] D. E. Rivadeneira, S. R. Steele, C. Ternent, et al., "Practice parameters for the management of hemorrhoids (revised 2010)," Dis. Colon Rectum, vol. 54, no. 9, pp. 1059-1064, 2011.

[19] P. Godeberge, P. Sheikh, V. Lohsiriwat, et al., "Micronized purified flavonoid fraction in the treatment of hemorrhoidal disease," J. Comp. Eff. Res., vol. 10, no. 10, pp. 801-813, 2021.

[20] V. S. Iyer, I. Shrier, P. H. Gordon, "Long-term outcome of rubber band ligation for symptomatic primary and recurrent internal hemorrhoids," Dis. Colon Rectum, vol. 47, no. 8, pp. 1364-1370, 2004.

[21] Adapted from J. Cintron, H. Abcarian, "Benign anorectal: hemorrhoids," in The ASCRS Textbook of Colon and Rectal Surgery, B. G. Wolff, J. W. Fleshman, D. E. Beck, et al., Ed., New York: Springer-Verlag, Inc, 2007, pp. 156-177.

[22] R. J. Longman, W. H. Thomson, "A prospective study of outcome from rubber band ligation of piles," Colorectal Dis., vol. 8, pp. 145-148, 2006.

[23] A. Izadpanah, S. Hosseini, M. Mahjoob, "Comparison of electrotherapy, rubber band ligation and hemorrhoidectomy in the treatment of hemorrhoids: a clinical and manometric study," Middle East J. Dig. Dis., vol. 2, pp. 9-13, 2010.

[24] American Gastroenterological Association, "American gastroenterological association technical review on diagnosis and treatment of hemorrhoids," Gastroenterology, vol. 126, pp. 1463-1473, 2004.

[25] R. Shekhar, V. K. Gupta, "Efficacy of foam sclerotherapy in treatment of grade I and grade II bleeding hemorrhoids at Nalanda Medical
College and hospital, Patna," Int. Surg. J., vol. 7, no. 9, pp. 2925-2928, 2020 .

[26] T. Yano T, Yano K, "Comparison of injection sclerotherapy between $5 \%$ phenol in almond oil and aluminum potassium sulfate and tannic acid for grade 3 hemorrhoids," Ann. Coloproctol., vol. 31, pp. 103-105, 2015.

[27] K. H. Moser, C. Mosch, M. Walgenbach, et al., "Efficacy and safety of sclerotherapy with polidocanol foam in comparison with fluid sclerosant in the treatment of first-grade haemorrhoidal disease: a randomised, controlled, single-blind, multicentre trial," Int. J. Colorectal Dis., vol. 28, pp. 1439-1447, 2013.

[28] O. Kaidar-Person, B. Person, S. D. Wexner, "Hemorrhoidal disease: A comprehensive review," J. Am. Coll. Surg., vol. 204, pp. 102-117, 2007.

[29] M. P. Ricci, D. Matos, S. S. Saad, "Rubber band ligation and infrared photocoagulation for the outpatient treatment of hemorrhoidal disease," Acta Cir. Bras., vol. 23, pp. 102-106, 2008.

[30] C. F. Marques, S. C. Nahas, C. S. R. Nahas, et al., "Early results of the treatment of internal hemorrhoid disease by infrared coagulation and elastic banding: a prospective randomized cross-over trial," Tech. Coloproctol., vol. 10, pp. 312-317, 2006.

[31] B. R. Kann, C. B. Whitlow, "Hemorrhoids: diagnosis and management," Tech. Gastrointest. Endosc., vol. 6, no. 1, pp. 6-11, 2004.

[32] V. Lohsiriwat, D. Lohsiriwat, "Ambulatory anorectal surgery under perianal anesthetics infiltration: analysis of 222 cases," J. Med. Assoc. Thai, vol. 90, pp. 278-281, 2007.

[33] E. K. Tan, J. Cornish, A. W. Darzi, et al., "Meta-analysis of short-term outcomes of randomized controlled trials of LigaSure vs conventional hemorrhoidectomy," Arch. Surg., vol. 142, pp. 1209-1218, 2007.

[34] J. Rakinic, "Benign anorectal surgery: management," Adv. Surg., vol. 52, pp. 179-204, 2018.

[35] J. F. Gravié, P. A. Lehur, N. Huten, et al., "Stapled hemorrhoidopexy versus Milligan-Morgan hemorrhoidectomy: a prospective, randomized, multicenter trial with 2-year postoperative follow up," Ann. Surg., vol. 242, pp. 29-35, 2005.

[36] P. Giordano, G. Gravante, R. Sorge, et al., "Long term outcomes of stapled hemorrhoidopexy vs conventional hemorrhoidectomy," Arch. Surg., vol. 144, no. 3, pp. 266-272, 2009.

[37] N. Malyadri, V. J. Allu, "A prospective comparative study of stapler hemorrhoidectomy vs open hemorrhoidectomy (Milligan Morgan) in its outcome and postoperative complications," J. Surg. Res., vol. 4, no. 1, pp. 4-13, 2021.

[38] P. O. Nyström, N. Qvist, D. Raahave, et al.; Stapled or Open Pile Procedure (STOPP) trial study group, "Randomized clinical trial of symptom control after stapled anopexy or diathermy excision for haemorrhoid prolapse," Br. J. Surg. vol. 97, pp. 167-176, 2010.

[39] C. Ratto, L. Donisi, A. Parello, et al., "Evaluation of transanal hemorrhoidal dearterialization as a minimally invasive therapeutic approach to hemorrhoids," Dis. Colon Rectum. vol. 53, no. 5, pp. 803$811,2010$.

[40] C. G. Karadeniz, O. Irkorucu, B. H. Ucan, et al., "Fournier's gangrene after open hemorrhoidectomy without a predisposing factor: report of a case and review of the literature," Case Rep. Gastroenterol., vol. 3, no. 2, pp. 147-155, 2009.

[41] S. P. Brodovskyi, A. G. Iftodiy, I. M. Kozlovska, "Optimization of surgical treatment of hemorrhoidal disease stages III-IV," Klin. Khir. vol. 2017, no. 2, pp. 10-12, 2017. 